\title{
A NEW DETECTOR FOR A GAS CHROMATOGRAPH USING ELECTRON CURRENT FOLLOWING GLOW DISCHARGE
}

\author{
Masaji MochIzUKI AND Yoshikazu KAWAKAmI \\ Division of Physiology, Research Institute of Applied Electricity, \\ Hokkaido University, Sapporo, Japan
}

When a flowing gas sample containing $\mathrm{N}_{2} \mathrm{O}$ is luminously discharged at a low pressure, a "Nachleuchten" or afterglow is observed at the portion distal to the discharge electrodes. MochizuKI and others ${ }^{1)}$ have utilized this afterglow to analyse $\mathrm{N}_{2} \mathrm{O}$ by determining the relationship between the light intensity of the glow and the concentration of $\mathrm{N}_{2} \mathrm{O}$. In connection with this, the present authors measured the space charges along the discharge tubing, using LANGMUIR's single collector electrode ${ }^{2)}$. The first aim of the measurement was to determine whether the afterglow was produced by some specific combination of positive and negative ions, or positive ions and electrons. However, no such combination was observed, but the change in the electron current in pure $\mathrm{N}_{2}$ was confirmed by mixing small amounts of other gases such as $\mathrm{N}_{2} \mathrm{O}, \mathrm{O}_{2}$ and $\mathrm{CO}_{2}$. The results of this study inspired further investigation to determine whether this method is applicable as a detector in gas chromatography.

Hitherto many ionization methods have been used as detectors in gas chromatography ${ }^{3,4}$. Most of them have measured the ion currents in accelerating electric fields, however, the present method measures the electron current which follows the luminous discharge without applying any electric fields. The results obtained are fairly reproducible and no complicated and expensive equipment is required.

\section{METHOD}

The apparatus consists of two parts, a chromatographic column and a detector as illustrated in FIG. 1. The detector is similar to the discharge tube reported in a previous paper concerning $\mathrm{N}_{2} \mathrm{O}$ analysisis ${ }^{1)}$ except for three collector electrodes. These collector electrodes are sealed at $5 \mathrm{~cm}$ intervals, in the distal portion of the discharge electrodes. Each electrode is a ring of $0.3 \mathrm{~mm}$ Pt wire, set in a glass tube

Received for publication May 28, 1965.

望月政司，川上義和 


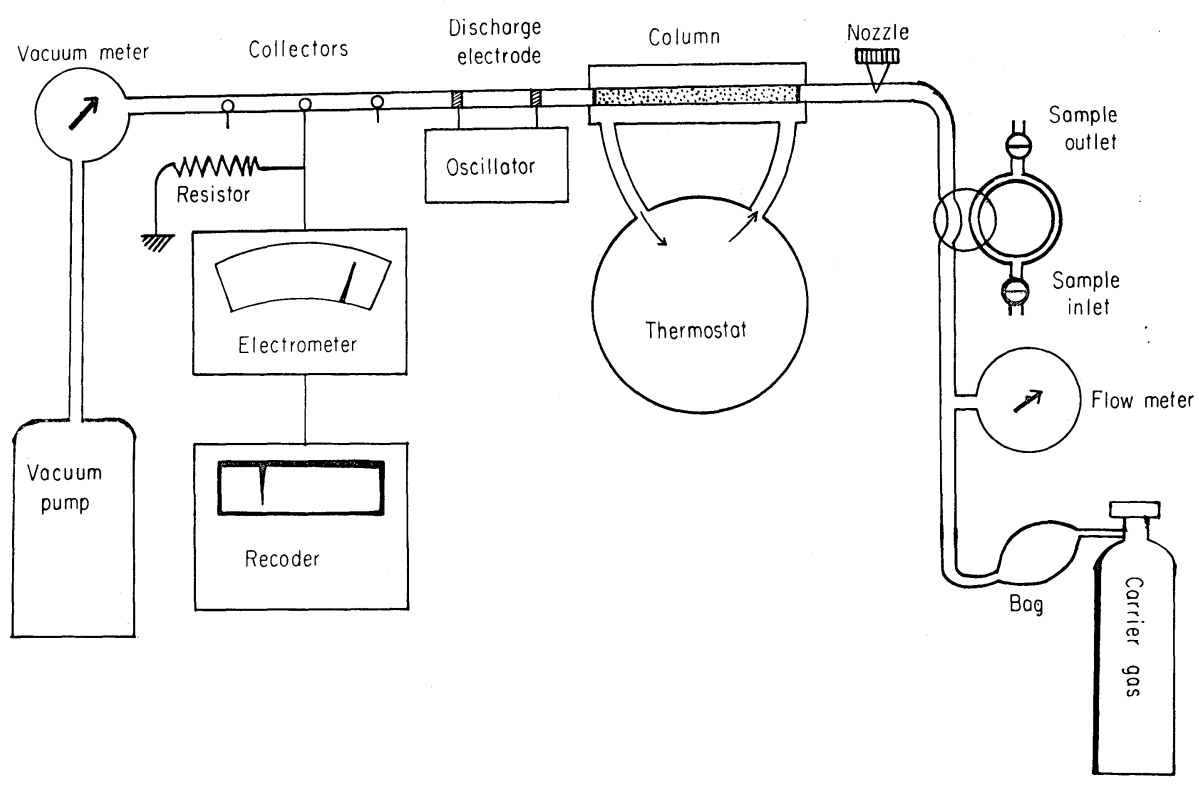

Fig. 1. Diagram of the apparatus.

(I. D. $4 \mathrm{~mm}$ ). They are grounded through high resistors (108 to $10^{10} \mathrm{ohms}$ ).

The column is composed of a glass tube (I. D. $4 \mathrm{~mm}$ ) filled with activated char. coal (60-80 mesh). A constant temperature was maintained in the column by circulating heated water $\left(50\right.$ to $\left.75^{\circ} \mathrm{C}\right)$. In order to secure a constant sample volume, a bypass for the carrier gas was set at the inlet of the column.

The electrode potential was measured by an electrometer (Takeda Riken Co. Tokyo) using a vibrating capacity method. The discharge tube was exposed to room temperature, the vacuum pressure was set at $4 \mathrm{mmHg}$, and the flow rate of the carrier gas at $20 \mathrm{ml}$ per min.

\section{RESULTS}

The electrode potential varied greatly with the resistance through which the electron current was led to the ground. When the resistance was higher than $10^{10} \mathrm{ohms}$, the electrode potential was unstable and also required a slow response time. Therefore, both $10^{8}$ and $10^{10} \mathrm{ohm}$ resistors were used in most of the experiments.

The actual record shown in FIG. 2 was obtained when $2 \mathrm{ml}$ of a gas mixture of about $20 \% \mathrm{O}_{2}, 5 \% \mathrm{CO}_{2}, 40 \% \mathrm{~N}_{2} \mathrm{O}$ and $35 \% \mathrm{~N}_{2}$ was carried with $\mathrm{N}_{2}$ through a $20 \mathrm{~cm}$ column. This curve was recorded through an electrode $15 \mathrm{~cm}$ from the discharge electrode and through a $10^{8}$ resistor. Successive peaks of $\mathrm{O}_{2}, \mathrm{CO}_{2}$ and $\mathrm{N}_{2} \mathrm{O}$ appeared on the curve. The peak heights were influenced by many factors such as the flow rate, the vacuum pressure, the discharge voltage, and the distance between the collector and the discharge electrode. 


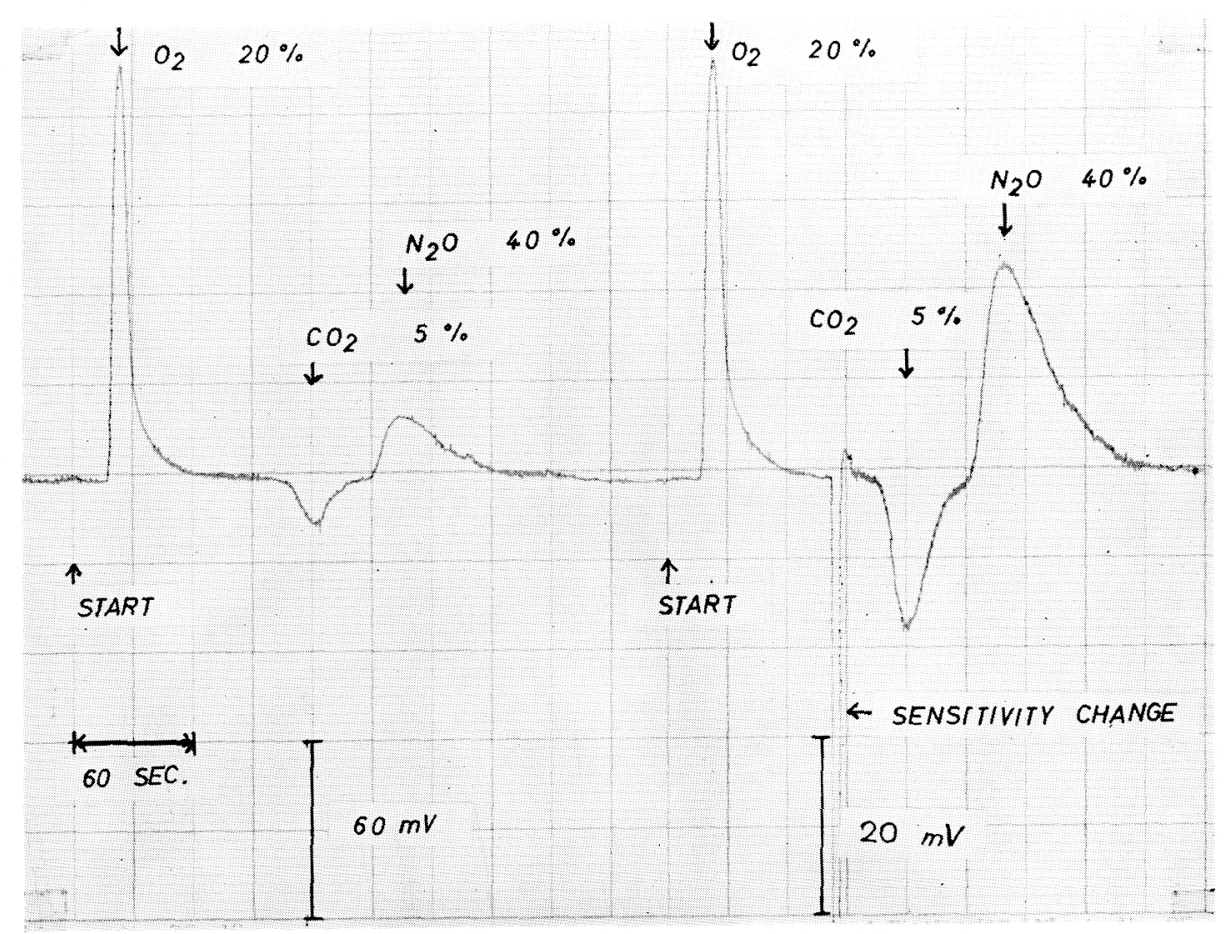

FIG. 2. An actual record of a gas mixture containing $\mathrm{O}_{2}, \mathrm{CO}_{2}$ and $\mathrm{N}_{2} \mathrm{O}$. Carrier: $\mathrm{N}_{\mathrm{z}}$, Column: Activated Charcoal $20 \mathrm{~cm}$, Temperature: $50^{\circ} \mathrm{C}$, Flow: $20 \mathrm{ml} / \mathrm{min}$, Vacuum Pressure: $4 \mathrm{mmHg}$.

However, when these factors were kept constant, the peak height was stable and was proportional to the concentration of the test gas.

FIG. 3 and 4 show the calibration curves for peak $\mathrm{O}_{2}$ and $\mathrm{CO}_{2}$ potentials plotted against their concentrations as measured by ScHOLANDER's apparatus. These three curves were obtained through three different collector electrodes. The $\mathrm{O}_{2}$ peak pontentials decreased exponentially with an increase in the distance between the discharge and collector electrodes. When this distance was $5 \mathrm{~cm}$, the electron current was about 5 times greater than when this distance was $10 \mathrm{~cm}$. In every case, the $\mathrm{O}_{2}$ calibration curves showed gradual decreases as the $\mathrm{O}_{2}$ concentration increased. On the other hand, the $\mathrm{CO}_{2}$ peak potentials decreased as the collector electrodes approached the discharge electrodes. No peak such as is shown in Fig. 2 was actually observed at the first electrode. As may be seen in FIG. 4, the ratio of peak heights at the second electrode to those at the third, was not as large for $\mathrm{CO}_{2}$ as it was for $\mathrm{O}_{2}$.

When the resistance was $10^{10}$ ohms, the peak potentials were about 100 times greater than those at $10^{8} \mathrm{ohms}$. However, the calibration curve changed for the worse, probably because of the potential change in the collector electrode produced by the electron current. 


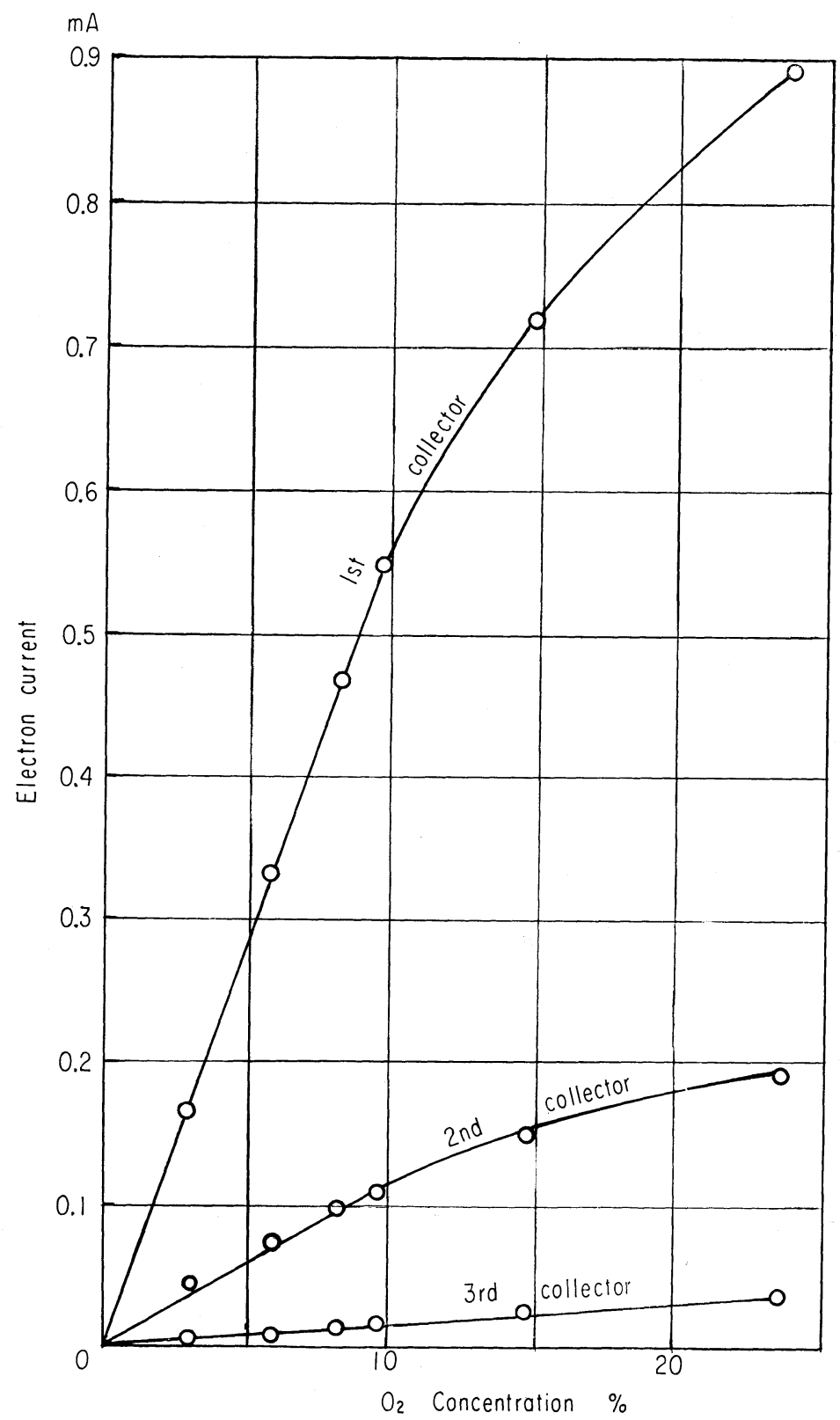

FIG. 3. $\mathrm{O}_{2}$ calibration curve. 


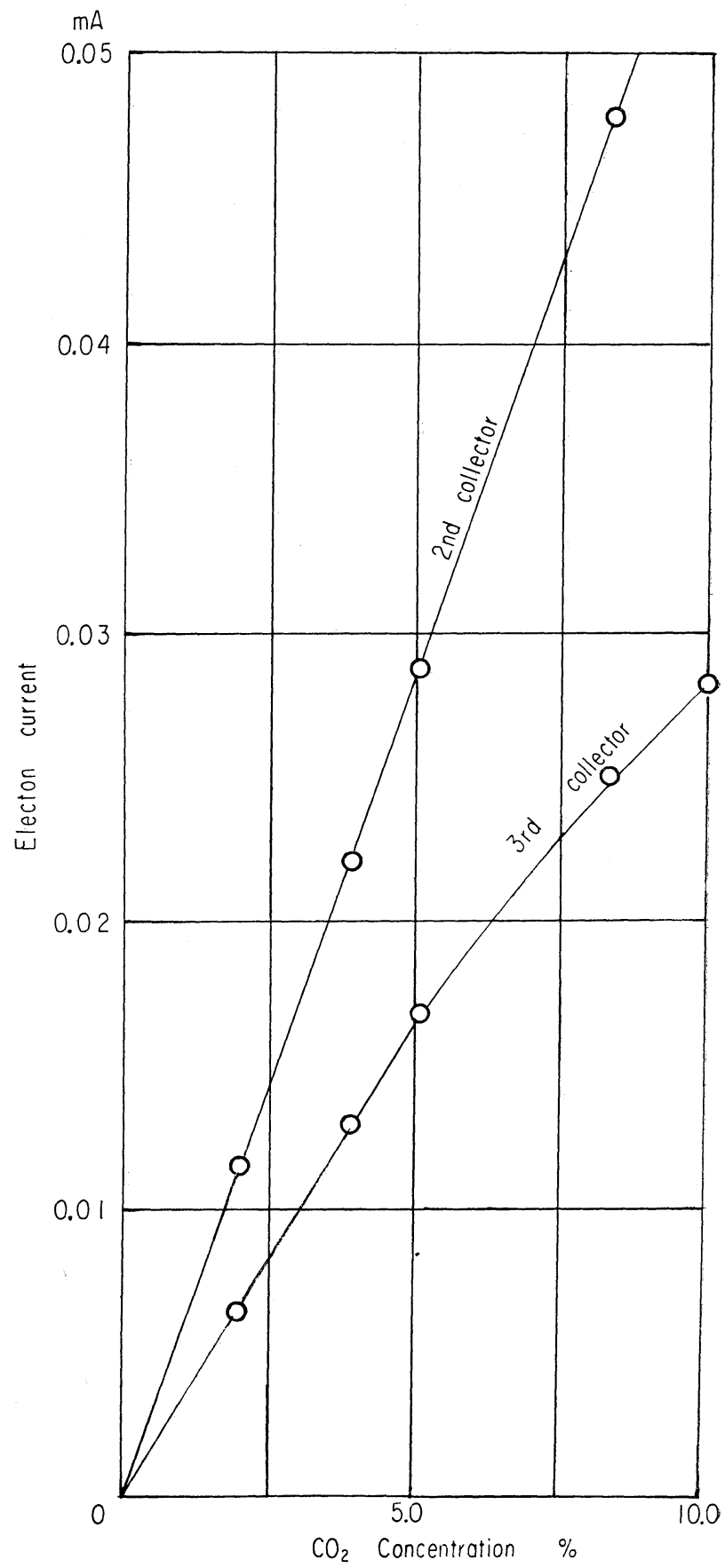

FIG. 4. $\mathrm{CO}_{2}$ calibration curve. 


\section{DISCUSSION}

Investigation of the space charge in plasma was first reported by LANGMUIR and MotT-SMith in 1924. They observed the electron and the ion currents by inserting a single collector electrode in a discharging fields. As is described in their report, because of the small mass and consequent high mobility of electrons, electron current densities in uniformly ionized gases may be hundreds of times greater than the positive ion current densities. In the present study, the collector electrode was simply leaked to the ground through a $10^{8} \mathrm{ohm}$ resistor, and no voltage was applied to it, therefore, the observed current must be roughly equal to the electron current.

The method utilizing the luminous discharge had already been developed by Pitckethly in $1958^{5}$. His method is based on the principle that the discharge current depended upon the concentration of test gas at a constant discharge voltage. According to LoveLOCK ${ }^{3)}$, in this method, the organic compounds are decomposed to their constituent elements when discharged, and the deposition of carbon on the surface of the cathode following such decomposition can profoundly alter its emission of electrons. However, in the present method, the discharge electrodes are set outside the glass tube, and the collector electrode is away from the discharge electrode. Therefore, the alteration of sensitivity will be greatly improved, even for measurements of organic compounds. Since no applied voltage to the collector electrode is required, the apparatus is more simple than PickeTHLY's.

At present, it is certainly not clear, whether the change in the electron current is produced by the capture of electrons by some test gas, or by a net change in the number of electrons in the discharge field. As has already been described, the $\mathrm{CO}_{2}$ peak disappeared at the first electrode, and the greatest peak was seen at the second electrode. Therefore, as far as $\mathrm{CO}_{2}$ is concerned, the peak may have been produced by the capture of electrons by $\mathrm{CO}_{2}$ molecules during travel from the discharge portion to the collector electrode.

Although the $\mathrm{O}_{2}$ calibration curve was not linear, as is shown in Fig. 3, it will attain linear characteristics, if the sample volume is reduced from 2 $\mathrm{ml}$ to somewhat less. Furthermore, this has the following two advantages: the $\mathrm{CO}_{2}$ peak appears on the opposite side of the $\mathrm{O}_{2}$ on the recorded curves, and $\mathrm{N}_{2}$ can be used as a carrier gas for the $\mathrm{O}_{2}$ determination. Therefore, this method may be useful in analysis of respiratory gases.

\section{SUMMARY}

From the fact that the electron current following a glow discharge of $\mathrm{N}_{2}$ was markedly influenced by mixing a small amount of other gases, a new 
detector for a gas chromatograph was designed. The glow discharge was generated by applying $2-3 \times 10^{3} \mathrm{~V}$ of $1 \mathrm{Mcps}$ from outside the glass discharge tube.

The electron current was measured through three single collector electrodes sealed at different positions, 5,10 and $15 \mathrm{~cm}$ distant from the discharge electrodes. The detector was sensitive to both $\mathrm{O}_{2}$ and $\mathrm{CO}_{2}$, and their peaks appeared on opposite sides of the $\mathrm{N}_{2}$ level.

Since $\mathrm{N}_{2}$ gas may be used as the carrier gas, and the structure of the equipment is very simple, this detector may be very useful in analysis of respiratory gases.

\section{REFERENCES}

1) Mochizuki, M., Ota, Y., Kamimura, Y. And Miyamoto, Y: Jap. J. Physiol. 14 : 599, 1964.

2) Langmuir, I. And Mott-Smith, H.: Gen. Electr. Rev. $27:$ 449, 1924.

3) Lovelock, J.E.: Anal. Chem. 33: 162, 1961.

4) Schomburg, G.: Z. Anal. Chem. 189: 14, 1962.

.5) Pickethly, R.C.: Anal. Chem. $30:$ 1310, 1958. 